\title{
PAUL VIDAL DE LA BLACHE (1845-1918) \\ PARA ALÉM DA INGENUIDADE: RELEITURAS VIDALIANAS
}

É com muita satisfação que este periódico apresenta Leçon d'ouverture du cours de Géographie (1899), palestra inicial de Paul Vidal de la Blache na ocasião de seu ingresso na Sorbonne, a mais prestigiosa e importante das universidades francesas. Após ter lecionado no liceu de Angers, na École Supérieure des Lettres et Sciences de Angers e na Universidade de Nancy a partir da década de 1870, Vidal conquista Paris devido à aposentadoria de Louis-Auguste Himly (1823-1906). Entretanto, a despeito de seus indubitáveis atributos intelectuais, por intermédio daqueles que apoiaram sua nomeação é possível perceber as inclinações políticas que moviam o campo universitário francês durante a III República: trata-se de gente como Marcel Dubois (1856-1916), fundador dos Annales de Géographie (1891) ao lado de Vidal e primeiro ocupante da cadeira de Geografia Colonial (1892), e Ernest Lavisse (1842-1922), um dos principais historiadores da Escola Metódica, cujo livro didático consistia num ardoroso credo político, ideológico e nacionalista a instruir lições de civismo e patriotismo. ${ }^{1}$

Só esses elementos já seriam suficientes para que não lêssemos Vidal de maneira apolítica - conforme, infelizmente, tem sido praticado na

${ }^{1}$ O prefácio de sua última edição (1912) é assaz revelador. Mexer com a história era mexer com os brios da nação: "Se o aluno não carregar consigo a lembrança viva de nossas glórias nacionais; se não souber que seus ancestrais combateram em mil campos de batalhas por causas nobres; se não aprender que custou sangue e esforços fazer a unidade de nossa pátria e em seguida resgatar do caos de nossas instituições envelhecidas as leis que nos fizeram livres; se não se tornar o cidadão compenetrado de seus deveres e o soldado que ama seu fuzil, o professor primário terá perdido o seu tempo" (LAVISSE apud DOSSE, 1992:41 [1987]). Aqui, menos que a citação em si, importante é enfatizar que o livro mais célebre de Vidal, o Tableau de la géographie de la France (1903), foi publicado pela primeira vez abrindo a imponente coleção Histoire de France: de l'époque gallo-romaine à la Révolution, composta de nove tomos e dezessete volumes que aparecerão entre 1901 e 1911. Seus traços mais característicos são o Estado-nação como objeto a ser privilegiado; a periodização segundo os reinos e seus nomes ilustres; relevo sobre os fatos políticos, diplomáticos e militares. Seu organizador? Ernest Lavisse. 
maioria das vezes. Mesmo aqueles que se esforçaram em trazer a dimensão política para a Geografia optaram por escolher a pior das estratégias: a tentativa equivocada de despolitização do pensamento vidaliano tanto o empobreceu quanto o relegou a um plano inferior (LACOSTE, 1988 [1976]). Sua proposta de reabilitá-lo não parece ter logrado êxito (LACOSTE, 1994 [1917]) - sobretudo no Brasil, onde Vidal continua sendo visto como a parte despropositada e irrelevante dos cursos de Introdução à Geografia e História do pensamento geográfico, personagem máximo de uma Geografia "simplória e enfadonha" que deve ser esquecida o mais depressa possível (LACOSTE, 1988 [1976]).

Todavia, embora o artigo em questão não deixe de apresentar um intelectual preocupado com as questões políticas de seu tempo, seu núcleo aponta para outra direção. Afinal, tratava-se de ocasião solene em que o cientista, comprometido com a "neutralidade" de seu ofício, ambicionava ser reconhecido por seus pares através do valor de suas ideias. E é com esse intuito que Vidal pronuncia sua lição inaugural: tratava-se de delimitar um campo de conhecimento, definir seu método, estabelecer as bases epistemológicas. Aqui, mais uma vez, nosso investigado desmente a interpretação habitual que dele se opera: longe de ser um geógrafo empirista e descritivo que faz da observação sua principal ferramenta analítica, Vidal nos brinda com um instrumental teórico-metodológico dos mais complexos e avançados de sua época: comparação, totalidade, unidade entre as ciências, articulação passado-presente, valorização da diversidade humana e de seus espaços, relevância social da natureza, atração pela civilização material...

Portanto, embora o ex-aluno Camille Vallaux tenha dito que "Vidal nunca quis definir seu pensamento atribuindo-lhe contornos muito nítidos" (apud CLAVAL, 2007:63), e Berdoulay tenha apontado "quase que uma ausência de referências a filósofos e outros pensadores da problemática da pesquisa científica" (1995:183 [1981]), cremos ser possível edificar outro caminho analítico. De fato, existe um conjunto de noções e conceitos que nos permite falar em uma epistemologia vidaliana. Na realidade, esta é a tônica de boa parte de seus escritos: quando não está tratando diretamente de questões teóricas (VIDAL DE LA BLACHE, 1896, 1902, 1903, 1908, 1913), todo e qualquer tema fornece a ele a possibilidade de uma meditação dessa estirpe. Este é um ponto importante: casos empíricos variados representam uma oportunidade de repensar a teoria. Ou, o que é a mesma coisa, existe uma teoria por trás da apreensão das mudanças empíricas. É assim que a dinâmica urbano-industrial conduz a uma modificação da vida regional, impondo a necessidade de uma nova regionalização do território francês (VIDAL DE LA BLACHE, 1911, 
1917); os meios de transporte e a maquinaria modificam a relação dos grupos com os lugares, complicando ainda mais o jogo de escalas (VIDAL DE LA BLACHE, 1916); os saberes locais de camponeses e pastores, agentes multisseculares no trato com a terra e com a natureza, deveriam ser incorporados pelos geógrafos profissionais, e não desdenhados como se fossem irrelevantes (VIDAL DE LA BLACHE, 1996-97 [1902]).

É bem verdade que, na constituição do campo das Ciências Humanas no decorrer do século XX, o conceito de teoria parece ter se enrijecido e assumido um tom formalista - sobretudo quando da insistência em separar o "senso comum" da ciência, valorizando esta em detrimento daquela. Nessa trilha, uma das principais críticas voltadas ao período clássico diz respeito à fragilidade de um perfil teórico que autorizasse a cientificidade da Geografia - configurando mesmo um ponto de convergência entre autores tão diferentes como Carl Sauer, Richard Hartshorne e Fred Schaeffer (GOMES, 1996). Todavia, o empenho vidaliano de institucionalizar a Geografia na universidade e ampliar seu raio de ação pedagógico; demarcar o campo de atuação do geógrafo frente aos historiadores, geólogos e sociólogos sem, no entanto, abrir mão da interdisciplinaridade; conceber certos conceitos e aplicá-los a situações concretas; e fornecer à Geografia uma visão coerente que possibilitasse o tratamento de temas variados não pode ser desprezado quando se discute a questão da construção do conhecimento científico.

Destarte, uma vez admitindo esse trabalho como um de seus mais importantes textos epistemológicos, dois aspectos são centrais em sua elaboração: (i) a historicidade dos fenômenos geográficos; (ii) a Terra vista em sua totalidade. No entanto, longe de aparecerem somente nesse texto, eles compõem a base da Geografia Humana vidaliana - ao lado da interdisciplinaridade, da comparação e, evidentemente, das relações homem-meio. Elementos constantes dessa Geografia, tais relações são o núcleo em cujo redor gira todo o enredamento da vida social. As esferas política, econômica, cultural e social possuem uma autonomia que não é senão relativa, na medida em que estão inexoravelmente ligadas ao meio em que foram engendradas. E é esse mesmo meio que se constitui em locus privilegiado para a observação dos desdobramentos de tais esferas. Desse modo, o tratamento geográfico da política localiza-se na conquista territorial; da economia, na capacidade técnica de extração dos recursos e de articulação entre as escalas para fins de circulação; da cultura, na identidade com o lugar; e da sociedade, na adaptação ao meio.

Consagrado como geógrafo porém historiador de formação (aliás, sua opção pela Geografia ainda permanece insuficientemente esclarecida - 
cf. OZOUF-MARIGNIER, 2000), Vidal não abre mão de recuperar o processo histórico para esclarecer os temas geográficos - quer seja na análise das fronteiras do leste francês (VIDAL DE LA BLACHE, 1919), quer seja na compreensão das paisagens (VIDAL DE LA BLACHE, 1908). No presente texto, ao comentar a herança intelectual de Himly em torno da formação territorial da Europa moderna, diz que "uma das razões pelas quais o espírito histórico tem seu papel marcado na geografia é que ele é o único capaz de estabelecer aos fatos toda sua signifícação e alcance" (VIDAL DE LA BLACHE, 1899:98). Vidal sabia muito bem disso. Afinal, uma década antes, publicara États et nations de l'Europe nessa mesma perspectiva (VIDAL DE LA BLACHE, 1889). Por isso, ele interpretava os Estados modernos como "complexas combinações de geografia e história" (VIDAL DE LA BLACHE, 1899:99), vislumbrando o mapa político não como algo estático, ${ }^{2}$ mas sim "um testemunho que evoca o passado" (idem).

Entretanto, em termos geográficos, a dimensão histórica também deve ser capaz de explicar a dinâmica da natureza, pois, "no mundo físico como nas coisas humanas, o presente não se compreende sem o passado" (ibidem, p. 106). É uma temporalidade muito mais ampla e complexa que a cronologia, então hegemônica graças aos historiadores da Escola Metódica. Não por acaso, a grande reviravolta na historiografia, os Annales de Marc Bloch e Lucien Febvre, terá como uma de suas principais matrizes a Geografia vidaliana. Ela promove interrogações como as seguintes: "A ação da natureza não foi submersa e como que abafada sob a massa acumulada de fatos históricos? Há 2.500 anos - isso para falar apenas da Europa Central - que uma via histórica intensa não cessa de complicar as causas e os efeitos" (ibidem, p. 98-99). Daí a relevância de Vidal na principal inovação epistemológica promovida pelos Annales e desenvolvida magistralmente por Fernand Braudel: a longa duração (RIBEIRO, 2008).

No que diz respeito ao segundo aspecto acima evocado, a Terra é uma escala de referência, no sentido da totalidade e do conjunto no qual as demais escalas estariam inseridas. Representa a base comum na qual

2 Vidal não perdia de vista o senso crítico em torno da démarche geográfica: da pertinência da Cartografia como recurso utilizado pela Geografia Política, exorta que, "por mais variados que sejam ou que possam vir a ser seus meios de expressão, [ela] não será suficiente para a explicação dos fatos", os quais carecem de "uma interpretação atenta" a fim de não negligenciar a complexidade encoberta por trás de uma lista de nomes e demarcações fronteiriças (VIDAL DE LA BLACHE, 2002:137 [1898]; grifo nosso). 
repousam as vidas humana, animal e vegetal, sujeitas às interferências climáticas e geológicas. Independentemente de a Geografia estudar a diferenciação paisagística e regional, o pressuposto da unidade terrestre permitia a apreciação de que os lugares não só dependiam uns dos outros, como se influenciavam mutuamente. Antes de tudo, é ao observar a dinâmica da natureza que Vidal retira a noção de totalidade: as correntes marítimas, a circulação climática e o modelado do relevo afetam grandes extensões da superfície terrestre, tal como os exploradores dos séculos XV e XVI puderam comprovar. O progresso das ciências estava diretamente ligado às mudanças históricas, e a descoberta de áreas outrora desconhecidas pelos europeus iluminava o que antes não passava de especulação. A Expansão Europeia, a Revolução Científica e o Imperialismo permitiram uma nova interpretação do espaço terrestre.

Porém, Vidal está longe de ser um naturalista ou um geógrafo que via apenas as características físicas como único critério a ser adotado na delimitação regional. Muito pelo contrário: ao acompanhar de perto sua trajetória, foram identificados oito conceitos de região, demonstrando uma transição em que o modelo naturalista vai se dissolvendo diante do predomínio das questões econômicas (OZOUF-MARIGNIER e ROBIC, 1995). As concentrações urbanas traziam consigo uma nova geografia econômica que, por sua vez, costurava combinações territoriais tão originais quanto as nodalidades, isto é, a atração das cidades umas em relação às outras de maneira a reunir as demandas impostas pela vida comercial e industrial (VIDAL DE LA BLACHE, 1913). Consequentemente, as divisões administrativas restavam caducas em face dessa nova dinâmica, e sua proposta atingia em cheio o passado e o futuro franceses: o imperativo categórico por uma nova regionalização do território francês (VIDAL DE LA BLACHE, 1913, 1917).

De fato, uma concepção real da escala mundo começava a ser desenhada, permitindo um enfoque de tipo comparativo. Uma visão pontilhista não se sustentaria caso não se juntasse ao conjunto geral dos fenômenos. Não se tratava de uma substituição, mas de uma integração da parte ao todo, do particular ao geral; tampouco do enciclopedismo vago e genérico, mas da necessidade de conexão entre as escalas. Não existe, portanto, dicotomia entre a Geografia Geral e a Geografia Regional, na medida em que as escalas dependem umas das outras (VIDAL DE LA BLACHE, 1913:292). Por mais que o geógrafo delimitasse seu objeto, isso não significava sua restrição escalar, pois os princípios que constituem a base de sua elucidação vivem uma relação de mútua influência junto a outras escalas. Não existe lugar que se explique por si só, pois compreender as causas dos fatos demanda a conjunção de elementos 
esparsos (VIDAL DE LA BLACHE, 1899:101). E a conjuntura vivida por Vidal foi essencial, impelindo-o a assinalar o desenraizamento causado pelo maquinismo, as cidades como polos de poder e a diminuição das distâncias como manifestações da emergência de uma nova configuração escalar. Igualmente, a visada geopolítica examinando a posição da França (sobretudo o Leste) no continente europeu, comparando o Império Francês ao Império Britânico e atentando às relações de seu país com a América do Sul, são exemplos valiosos que mostram não somente o raio de ação de seu pensamento, mas o poder da análise multiescalar.

Portanto, não há nada que justifique a interpretação de que a região vidaliana seja um "conceito-obstáculo", como se tivesse os olhos vendados em relação ao todo ou fosse uma perspectiva ciclópica a impedir uma visão ampliada e articulada da realidade. ${ }^{3}$ Melhor dizendo, há, sim, uma justificativa a legitimar tal leitura: a ingenuidade da Geografia brasileira ao negligenciar a história do pensamento geográfico.

\section{Guilherme Ribeiro}

UFF-Campos dos Goytacazes

\section{Bibliografia}

BERDOULAY, V.,(1995 [1981]). La formation de l'école française de géographie. Paris: Éditions du CTHS.

CLAVAL, P. (2007). Géographies et géographes. Paris: L'Harmattan.

DOSSE, F. (1992 [1987]). A História em migalhas: dos “Annales" à Nova História. Campinas: Ed. Unicamp/Ensaio.

GOMES, P. C. da C. (1996). Geografia e modernidade. Rio de Janeiro: Bertrand Brasil.

LACOSTE, Y. (1994 [1917]). Préface. In: VIDAL DE LA BLACHE, P. La France de l'est (Lorraine-Alsace). Paris: La Découverte.

3 “Nesse domínio de reflexão, o conceito-obstáculo da 'região' vidaliana exerceu, em cheio, seus efeitos de bloqueamento, e isso paralisou as pesquisas teóricas que teriam permitido perceber de maneira racional e eficaz as confusões da espacialidade diferencial. Não somente aquela não foi vista (...), mas ela foi negada pela inculcação de uma representação de mundo, feita de uma série de compartimentos bem estanques, 'soitdisant' dados pela natureza e a história, por Deus, uma vez por todas e nitidamente separados uns dos outros: as regiões, cada uma designada por um nome próprio para melhor acreditar em sua "individualidade"” (LACOSTE, 1988:192-193 [1976]). 
. (1988 [1976]). A Geografia: isso serve, em primeiro lugar, para $\overline{\text { fazer a }}$ guerra. Campinas: Papirus.

OZOUF-MARIGNIER, M.-V. (2000). Le Tableau et la division régionale: de la tradition à la modernité. In: ROBIC, M.-C. (Dir.). Le Tableau de la Géographie de la France de Paul Vidal de la Blache: dans le labyrinthe des formes. Paris: Éditions du CTHS.

OZOUF-MARIGNIER, M.-V.; ROBIC, M.-C. (1995). La France au seuil des temps nouveaux: Paul Vidal de la Blache et la régionalisation. L'Information Géographique, Paris, v. 59.

RIBEIRO, G. (2008). Espaço, tempo e epistemologia no século XX: a Geografia na obra de Fernand Braudel. Niterói: Tese (Doutorado) PPGEO-UFF.

VIDAL DE LA BLACHE, P. (1889). États et nations de l'Europe. Paris: Armand Colin.

. (2002 [1896]). O princípio da Geografia Geral. Geographia: revista da Pós-Graduação em Geografia da UFF, Niterói, ano III, n. 6.

. (2002 [1898]). A Geografia Política: a propósito dos escritos de Friedrich Ratzel. Geographia: revista da Pós-Graduação em Geografia da UFF, Niterói, ano IV, n. 7.

. (1899). Leçon d'ouverture du cours de Géographie. Annales de Géographie, ano VIII, n. 38.

. (1902). Les conditions géographiques des faits sociaux. Annales de Géographie, ano XI, n. 55, p. 13-23.

. (1996-97 [1902]). Routes et chemins de l'ancienne France. Strates [En ligne]. Crises et mutations des territoires, n. 9.

. (1903). La géographie humaine: ses rapports avec la géographie de la vie. Revue de Synthèse Historique, v. 7, ago./dez.

. (1908). De l'interprétation géographique des paysages. Neuvième Congrès International de Géographie, Genebra.

. (1911). La relativité des divisions régionales. Athéna (Conférence à l'École des Hautes Études Sociales).

. (1913). Les caractères distintifs de la géographie. Annales de Géographie, ano XXII, n. 112.

. (1916). Évolution de la population en Alsace-Lorraine et dans les départements limitrophes. Annales de Géographie, ano XXV, n. 133.

. (1917). La rénovation de la vie régionale. Foi et Vie, Les questions du temps présent, Cahier $\mathrm{B}, \mathrm{n} .9$, maio. 
. (1919). La frontière de la Sarre, d'après les traités de 1814 et de 1815. Annales de Géographie, ano XXVIII, n. 151. 


\title{
LIÇÃO DE ABERTURA DO CURSO DE GEOGRAFIA*
}

\author{
PAUL VIDAL DE LA BLACHE
}

Minha primeira palavra abrindo este curso deve ser uma homenagem de gratidão ao Conselho da Faculdade de Letras, pela honra que me foi feita ao designar-me, por suas eleições, ao ministro da Instrução Pública. Agradeço ao senhor ministro por ter bem abrigado e ratificado essa designação. Para mim, a acolhida que recebi desta ilustre casa é um encorajamento, pois foi dela que saí e experimentei, durante longo tempo, as alegrias de um ensino íntimo e familiar, cujas lembranças ainda me são caras.

Eu sinto uma temerosa honra por substituir o mestre que vocês estavam habituados a escutar. Sua palavra ainda ressoa nesta sala. Ouvindo as lições animadas por sua verve, não vinha à ideia de ninguém que o fim destes ensinamentos estava próximo. A cada ano, seus ouvintes o reencontravam nesta cadeira: sempre o mesmo, pleno de uma alegre energia. Por isso, é difícil para eles acreditar que o pensamento deste vigoroso espírito cedeu à tentação do repouso. E eis que, por quarenta anos, Himly aqui ensinou geografia e, depois de quase meio século, seu nome está fixado, para permanecer inseparável, ao nome desta casa! Nesta magnífica carreira universitária, tudo se ordena com retidão em uma unidade admirável. Seu exemplo como intelectual nos oferece uma ciência precisa e rigorosa, armada de bom senso, aguçada por uma crítica penetrante cuja veemência poderia se fazer temida caso não sentíssemos a escrupulosa justiça na qual seus julgamentos sempre se inspiravam. Como homem, por sua vez, inspirava confiança e respeito. Éramos tocados por sua cordialidade simples e forte que conferia tamanha autoridade a um conselho seu, bem como uma marca de estima e valor. Eu falava de respeito: que me seja permitido acrescentar aqui, entre aqueles que têm a honra de resgatá-lo, que esse sentimento se ilumina e se anima de uma respeitosa afeição.

Em seus livros, Himly condensou parte substancial de seu ensino. Nele, sentimos o pensamento de um historiador associado ao de um geógrafo. Uma das razões pelas quais o espírito histórico tem seu papel

* Conferência proferida na Faculdade de Letras de Paris em 7 de fevereiro de 1899 e publicada nos Annales de Géographie, ano VIII, n. 38, 15 mar. 1899. Tradução: Guilherme Ribeiro. Revisão técnica: Rogério Haesbaert 
marcado na geografia é que ele é o único capaz de estabelecer aos fatos toda a sua significação e alcance. Assim entendia Himly quando retraçava as grandes épocas da conquista do globo, por exemplo. Como o homem se emancipou, bem lentamente, das condições locais onde estava cercado, para estender sua vida além dessa condição? Como ele sobrepujou os obstáculos postos pela natureza ou criados pela sua imaginação? Por sua inclinação dramática, esta luta do homem contra o desconhecido liga-se a um interesse de ordem muito elevada. É um pouco uma história do espírito humano, que se liberta dos fantasmas e amplia suas visões e horizontes. Desejamos que Himly ainda nos conte algumas páginas desta história!

Entre as regiões de estudo, foi sobretudo a Europa que atraiu sua atenção. Dizia ele em 1876: "Reconduzido continuamente pelo meu ensino a estudar a ação e a reação incessantes da geografia sobre a história e da história sobre a geografia, tenho como empreitada escrever uma história da formação territorial da Europa moderna". Não saberíamos melhor definir a inspiração mestra de seus ensinamentos. Sem dúvida, a história política não é a única expressão das relações entre a natureza e o homem, mas ela a exprime em um de seus aspectos mais interessantes. A associação de palavras que Carl Ritter tinha inscrito no frontispício de sua Erdkunde natureza e a história dos homens - não é uma fórmula vã. Ademais, podese dizer que a cadeia que vai da natureza ao homem é composta de uma longa série de elos que, talvez, os contemporâneos de Ritter não imaginassem.

Tomando a Europa como campo de um estudo parecido, Himly não podia esconder que abordava o problema das relações natureza-história no que ele possui de mais complexo. A ação da natureza não foi submersa e como que abafada sob a massa acumulada de fatos históricos? Há 2.500 anos - para falar apenas da Europa Central - uma via histórica intensa não para de complicar as causas e os efeitos. Guerras, heranças, alianças e jogos de força e política entrelaçaram suas tramas. De tempos em tempos, bruscos relâmpagos têm atravessado esta história. Segundo a expressão de Himly, os homens estão se situando como "os grandes niveladores do começo do século", como indica o mapa atual da Alemanha.

Nesta extrema complicação, vê-se onde estaria o obstáculo. Comparações detalhadas entre a geografia física e uma determinada história correriam sério risco de ser superficiais. Não se trata de coincidências mais ou menos acidentais, mas de um amplo desenvolvimento humano a ser estudado em seu quadro.

A magistral obra de Himly instala o estudo político da Europa Central sobre uma base geográfica, mas trata a história historicamente. 
Após ter traçado um quadro pitoresco em que, em sua variedade de configuração e relevo, revê os países que se estendem dos Alpes ao mar, começa a desemaranhar o fio da meada dos fatos históricos. Assiste-se então ao longo trabalho pelo qual foram separadas as formas políticas que culminariam nos Estados modernos. Quando o imenso esforço do Império Romano para fixar os povos definitivamente malogrou, o conflito de raças se desprendeu dos quadros (tornados muito estreitos) da Europa Central. No contato com os eslavos, escandinavos e magiares, o germanismo se contrai e se fortifica. Constituem-se mercados, núcleo de futuros Estados. Feito assim pela reação invasora, o germanismo desenha pelo Danúbio e pelo Báltico seu alcance em direção ao Leste. Porém, durante este tempo, a velha Germânia transforma-se num variado mosaico: os domínios da Igreja se estendem, presas designadas ao apetite dos Estados adultos; sobre os rios e ao longo das costas, o comércio faz florescer cidades que tentarão formar ligas entre si (criações brilhantes, mas efêmeras); nos vales dos Alpes, no limiar das grandes passagens, constituem-se fortes comunidades de camponeses; sobre os rochedos isolados da Suábia e da Francônia ergue-se o burg $^{4}$ do "cavaleiro livre que depende apenas de Deus, de seu Imperador e dele mesmo". Entretanto, esta fragmentação não dura muito tempo. Vejam a Áustria, os Estados principescos e a Prússia que, nesta vida exuberante, dividem-se em partes. Assim, o mapa político é um testemunho que evoca o passado. Uns em seu benefício, outros para se fundir, todos esses fermentos trabalharam nestas associações chamadas grandes Estados modernos - complexas combinações de geografia e de história, em que a análise distingue uma série de diversos componentes: regiões naturais, domínios étnicos, terras de colonização e países de conquista, antigas individualidades políticas que tiveram seus momentos de vida. E, se esta variedade de elementos pôde tornar-se uma força, isso se deve à condição de que um poderoso espírito nacional se inflamou e se conservou para manter sua coesão.

Tais são alguns dos ensinamentos que Himly nos deu em suas lições e livros. Insistindo além disso, receio dar a impressão de esquecer que, se sua atividade professoral se impôs um fim, felizmente este não é o caso de sua atividade científica. E que ela nos reserve novos e preciosos ensinamentos. Assim, ele continuará a ser, para nós, o mestre que conhecemos. Nesta sala onde tudo a ele se seguia, aquele que tem a honra de tomar a palavra não poderia começar este curso sem evocar, seguindo a antiga expressão, melhores auspícios.

\footnotetext{
${ }^{4}$ Segundo o Dicionário Larousse, "palavra alemã que serve frequentemente para designar os castelos-fortes da Idade Média". (N.T.)
} 
Depois de alguns anos, assiste-se a um esforço de renovação dos estudos geográficos. Muito sensível não somente na Alemanha, mas na França, na Inglaterra, na Itália e em outros países da Europa, não é menos marcado nos Estados Unidos. Ele desperta a atenção das universidades e ecoa no público. Afirma-se pelas discussões mesmas que suscita. Dá lugar a trabalhos que, a despeito desta multidão enfadonha de escritos insignificantes que a geografia parece condenada a arrastar, atestam um esforço mais bem combinado e mais seguro.

Há toda a aparência de que este movimento irá se acentuar, e podemos nos perguntar quais são suas características e seu alcance.

De início, é importante considerar as novas condições nas quais se exerce o trabalho geográfico. Elas se modificaram e ainda se modificam todos os dias. Por quê? Basta considerar o desenvolvimento das invenções que contribuíram para nos libertar dos velhos entraves de distância e de tempo. Sem dúvida, esta é a maior mudança já produzida nas relações entre a Terra e o homem. Sob nossos olhos, temos um mapa que, com as redes de comunicação nele indicadas, parece dar uma imagem do domínio do homem sobre a Terra. Imaginemos, por exemplo, o telégrafo elétrico. Tal invenção tem feito mais pelo conhecimento da Terra do que o fizeram, em seu tempo, o relógio de sol, a bússola e o astrolábio. Forneceu o meio mais simples e mais seguro de precisar as longitudes (ao menos na Terra), trazendo assim a solução definitiva de um problema diante do qual a cartografia tinha se defrontado durante séculos. Criou o que chamamos, com razão, a geografia do ar, graças às correspondências que, centralizadas nos observatórios, permitiram preparar, a cada dia (pelas partes já conhecidas do globo), o mapa do tempo. Não podemos dizer que ele nos abriu o mundo dos mares? As primeiras séries coordenadas de sondagens que temos aprendido sobre o relevo dos oceanos vieram quando da instalação dos cabos submarinos.

Assim, o trabalho geográfico aproveita vantagens que não tinha conhecido. O homem exerce sobre o globo uma vigilância menos intermitente. Sem remontar ao tempo em que era necessário manter, em Lisboa, enviados especiais, ou espiões, para informar-se das descobertas do Novo Mundo - até nossos dias, esta era a realidade em Amsterdã, Paris, Londres e depois em algumas universidades alemãs que permaneceram concentradas em seus locais de trabalho. Hoje a enquete é múltipla, acontecendo ao mesmo tempo sobre os mais diferentes pontos do globo. Ela é servida por uma notoriedade científica que ainda está longe da 
perfeição, mas que já é suficiente para pôr os centros de estudo em comunicação mais rápida e mais direta. Certamente há diferenças nas maneiras pelas quais a geografia é feita no continente europeu, na Inglaterra e nos Estados Unidos; porém, é possível sentir por todos os lados, graças à penetração mais livre dos métodos e resultados, o enfraquecimento do particularismo científico e do indesejável "fechamento" em escolas estreitas. O trabalho é mais fecundo, pois é mais bem combinado. Com efeito, as regiões se explicam umas pelas outras. Para dar resultado, a pesquisa precisa ser feita em um certo número de regiões ao mesmo tempo. Para compreender as causas dos fatos, é necessário reunir o testemunho de fenômenos que podem estar separados e esparsos. Tomemos como exemplo uma das causas cuja ação ainda permanece diferentemente impressa sobre a fisionomia de certas regiões: os fenômenos glaciários. Por terem sido estudados não somente nos Alpes, mas no norte da Europa, na Groenlândia e na América, foi possível, pela via de indicações recíprocas, tocar o problema de perto. Foi na Suécia e na Groenlândia que encontraram explicações sobre o solo e a hidrografia da planície da Alemanha do Norte. ${ }^{5}$

Sob este impulso comum, multiplicam-se os grandes trabalhos. Refiro-me, sobretudo, a estes trabalhos coletivos e estas grandes associações que somente os Serviços de Estado podem empreender. No século XVIII, foi graças à Academia de Ciências, ao Observatório de Paris e à Sociedade Real de Londres que o mapa do mundo pôde ser fixado em suas grandes linhas. Foram necessários, em nossos dias, mais de cinquenta anos de trabalho e a colaboração de quase 800 empregados ou artistas, para o êxito das 273 folhas da carta topográfica da França. ${ }^{\circ}$ A obra foi concluída com tanto trabalho que estamos prontos a redobrar o sentido e o valor da preparação, na mesma escala, da carta geológica, cujo término (hoje próximo) será um título de honra para aqueles que asseguraram sua execução. Trabalhos semelhantes estão finalizados ou em curso não somente nos principais países da Europa, mas na Índia inglesa, em Java, no Japão, no Canadá e nos Estados Unidos. Na Rússia europeia, os nivelamentos de precisão, executados, sobretudo, depois de 1881, finalmente iluminaram a questão longamente debatida do relevo da planície oriental. O Observatório de São Petersburgo centralizou

${ }^{5}$ Otto TORELL, Zeitschrift der deutschen geologischen Gesellschaft, XXVII, 1875, p. 961.

${ }^{6}$ Carte de l'État-Major à 1:80000. As operações geodésicas e topográficas começaram em $1^{\circ}$ de abril de 1818; as geodésicas de primeira e segunda ordem terminaram em 1854; a triangulação de terceira ordem, em 1863; os levantamentos topográficos, em 1866; e a gravura, em 1882 . 
numerosos dados sobre o clima da parte europeia e asiática, e, na Rússia asiática, cinco centros de operação geodésica e topográfica estão em obra (sem contar a Comissão da Ferrovia Transiberiana). Assim, começamos a ver se desenhar, com precisão - quer dizer, com menos uniformidade e mais nuanças -, a fisionomia de um império que compreende a sexta parte da terra firme.

É verdade que os oceanos são menos conhecidos, e eles cobrem perto de três quartos da superfície do globo. Mas a Oceanografia já pode reunir-se, às publicações surgidas na América, na Escandinávia, na Alemanha, na Áustria, na Itália e na França, à imponente coleção de memórias científicas provenientes da expedição que começou em 7 de dezembro de 1872 num navio, de hoje em diante, memorável: o Challenger.

Para observar os fenômenos da camada atmosférica, deste Oceano fluido (seguindo a expressão de Humboldt) onde, na verdade, vivemos, e cujos movimentos transportam para longe a temperatura e a chuva, a rede de estações meteorológicas se estende. Grandes Serviços organizados na Europa, na América, no Japão e na Índia constituem, pouco a pouco, suas publicações de arquivos para o estudo dos climas. Ultrapassada em 25 anos, a série das Relações do Serviço Meteorológico indiano constitui um ciclo de precisos ensinamentos sobre uma parte desta zona terrestre que ainda não conhecemos o suficiente e que é, junto com as regiões polares, um grande laboratório de fenômenos climáticos: a zona tropical.

Notemos também os documentos de geografia humana entregues por estas grandes operações de recenseamento, tais como são entendidos nos Estados Unidos e na Índia inglesa: vastas investigações não somente sobre o número de habitantes, mas sobre sua repartição e os variados fenômenos relacionados à população.

A formação destes repertórios de fatos, coleções de ensinamentos e obras cartográficas está para a geografia assim como as grandes compilações, pacientemente constituídas após três séculos, estão para as ciências históricas e filosóficas. Partes significativas do globo ainda são imperfeitamente conhecidas, mas é um grande resultado que, desde agora, certas regiões situadas em condições de clima e de posição tão diferentes quanto Europa, América do Norte, Índia inglesa e Rússia asiática sejam campos de estudos suscetíveis de fornecer à ciência materiais de comprovada solidez. De tempos em tempos, obras de síntese e resumos 
substanciais saem destes ateliês científicos. ${ }^{7}$ A quantidade de campos de estudos não para de crescer. Desde já, sua existência é marcada pelo valor dos termos de comparação e de controle que eles nos fornecem, e, por mais incompleto que seja o edifício, agora há pilares que asseguram sua solidez.

Eu não falei do movimento de explorações que, particularmente entre nós, conciliou a geografia com numerosos e ferventes adeptos. É, portanto, um dos traços mais particulares deste período recente. Mas a importância destes resultados diz respeito, precisamente, à melhor organização do trabalho. Nosso século XIX tinha visto, antes de seu último quartel, grandes viagens conduzidas pelo interior dos continentes; a de Barth é um tipo de exploração científica que jamais foi ultrapassada. Mas eram explorações mais ou menos isoladas. Por volta de 1870, os resultados se agilizaram e os esforços se combinaram. Foi pouco a pouco em direção a este momento que se estimularam as grandes séries de explorações de que nossa geração foi testemunha: na África, onde Livingstone avançava, sem hesitar, em direção ao Congo; na Ásia central, onde os viajantes ingleses e os pundits indianos ${ }^{8}$ formados pelo Estado-Maior da Índia começavam a se engajar para além do Himalaia ao reencontro dos exploradores russos vindos do Norte; na Indochina, onde a expedição francesa do Mekong traçava suas vias a longas penas; e na América do Norte, onde se abordava o estudo do Grande Oeste. Para as pessoas que começavam a se interessar pela ciência geográfica, abria-se então uma fonte de novidades e revelações que não permitia que a atenção se relaxasse nem por um instante. Em 1870, o que se sabia das grandes cadeias da Ásia central, de sua extensão, estrutura e relações, vislumbradas com dificuldade? Gradualmente, elas estão saindo das sombras. Vimos então, durante dezoito anos, Prjavalski, um oficial-naturalista [officiernaturaliste] incansavelmente ocupado a rasgar/abrir de seus itinerários as solidões asiáticas; mas, ao mesmo tempo e após ele, outros viajantes russos e ingleses, mas também franceses, alemães, húngaros e suecos concorriam à mesma obra. E, à medida que os problemas precedentes eram

\footnotetext{
${ }^{7}$ Citemos: WILD, Die Temperaturverhültnisse des Russischen Reichs (São Petersburgo, 1881) - A Manual of the Geology of India, conforme as observações do Geological Survey por MEDLICOTT e W.T. BLANFORD; 2. ed. por OLDHAM (1893). - H.F. BLANFORD, A Practical Guide to the Climates and Weather of India (1889). - Os Atlas dos Oceanos publicados de 1882 a 1896 pela Deutsche seewarte (Atlântico, 1882; Oceano Índico, 1891; Pacífico, 1896). - A. ANGOT, Traité élémentaire de météorologie (Paris: Gauthier-Villars, 1899).

${ }^{8}$ Segundo o Dicionário Oxford, nativos da Índia treinados e empregados pelos ingleses para realizar levantamentos (surveys) em regiões inacessíveis para além das fronteiras britânicas. (N.T.)
} 
resolvidos, novos nasciam sobre seus passos. É também uma obra coletiva - e ainda mais metodicamente levada adiante - aquela inaugurada em 1870 pelo Geological Survey dos Estados Unidos alguns meses após a abertura da primeira ferrovia transcontinental. No momento em que a locomotiva começou a perturbar, nos desertos e oásis, os mórmons que lá tinham fundado a Nova Jerusalém, o interior das Montanhas Rochosas e mesmo seus acessos a $1^{\prime} \mathrm{W}$ do meridiano de $100^{\circ}$ ainda era um mundo quase desconhecido. Há dez anos, uma missão enviada ao Colorado não tinha feito mais que entrever a estranheza desta "província de platôs", "acumulação de rochas nuas, de formas gigantescas superpostas e coloração intensa", 9 que rasgam os canyons cravados por até $1.800 \mathrm{~m}$ de profundidade. Começa assim a exploração do Grande Oeste, e, por uma série de reconhecimentos sistemáticos, para além do alto Missouri e do sul do Rio Verde foi revelado em detalhes um dos tipos mais surpreendentes de região árida.

Se acrescentamos a estes exemplos outros que se apresentam a nosso espírito, vemos que o principal resultado deste período recente é o avanço do conhecimento sobre o interior dos continentes. Alexander von Humboldt tinha indicado esta aspiração da geografia e tentado, ele mesmo, supri-la parcialmente. Salvo exceções, até então os conhecimentos (e com eles as ideias geográficas) tinham sido concentrados, sobretudo, nas partes periféricas das terras, sobre aquelas onde o contato ou a vizinhança dos mares atenua os contrastes e multiplica as relações. Elas têm, certamente, um grande interesse; entretanto, estas não são as regiões mais próprias a fazer sentir o que a superfície do globo guarda de mais original. Pelas conquistas científicas que penetraram no mais profundo dos continentes, estamos nos familiarizando mais com aspectos terrestres que, até então, escapavam à observação. Neles, os fenômenos continentais se destacam vigorosamente. Lá estão os mais fortes contrastes oferecidos pela superfície terrestre: enormes diferenças de temperatura entre as estações e mesmo entre as horas do dia; ação pujante exercida sobre o modelado do terreno pelo gelo e pelos ventos; acumulação de restos de destruição nas grandes bacias sem escoamento em direção ao mar; poder mágico da água nos pontos de eleição onde ela aparece na superfície. Nestas regiões, tudo porta as marcas de uma adaptação rigorosa às exigências do ambiente: plantas, animais e mesmo os grupos humanos, pois o isolamento destas pequenas sociedades perdidas - descritas por alguns exploradores no

${ }^{9}$ IVES e NEWBERRY, Report upon the Colorado of the West, Washington, 1861. POWELL, Exploration of the Colorado River of the West, Washington, 1875. 
interior dos continentes ou nas extremidades do mundo habitável - tem as desarmado diante da tirania das condições naturais. ${ }^{10}$

Por estas descobertas, parece que a fisionomia da terra está sendo acentuada. Temos visto a obra de agentes físicos dos quais não suspeitávamos a importância. Temos sido postos na presença de energias terrestres cujos efeitos não mensuramos. Não há exagero em dizer que outros aspectos da natureza e da vida serão revelados.

III

Desta compreensão mais ampla e complexa dos fatos resulta que compreendemos melhor seu modo de repartição. Um sentimento mais correto da ordenação do Cosmos penetra na geografia. Coisas que pareciam exceção agora entram nas regras. Por exemplo, podemos destacar que as diferenças tão acentuadas de clima (que surpreenderam os primeiros observadores) entre a Europa e o lado americano a ela defronte estão longe de ser traduzidas da mesma forma no espírito, depois que conhecemos as analogias que lhes eram correspondentes. A geografia sempre discernirá regiões que se distinguem por uma combinação de condições mais vantajosas, mas estes benefícios não comportam nenhuma ideia de exceção ou de privilégio absoluto.

Estes progressos ecoaram em todas as ciências que, sob os mais diversos nomes, se ocupam da Terra. Todo mundo sabe a importância crescente assumida pela geografia do presente, desde que ela é mais bem conhecida, para reconstituir a geografia do passado. Importância recíproca, pois as regiões cuja evolução geológica está em via de ser retraçada são, para nós, um precioso ensinamento. Nelas, pode-se ver por quais longínquas preparações e através de quais séries de destruições elas foram arranjadas (e, depois, desenhadas as formas atuais), discernindo por elas o que, no presente, é a herança de um estado anterior. Há, notadamente, nas direções seguidas por muitos rios e na repartição dos seres viventes, aparentes enigmas que não se explicam unicamente ao considerarmos os fatos da atualidade. Seria ingênuo ver, neles, exceções negligenciáveis. São indícios que provam que, no mundo físico como nas coisas humanas, o presente não se compreende sem o passado.

${ }^{10}$ Ver, p. ex., os Tedas na relação de NACHTIGAL (Sahara und Sudan, tomo I); os ribeirinhos do Lob nor no relato da segunda viagem de PRJEVALSKI; os Iacutos do Lena na exploração do barão DE TOLL (1893). 
A meteorologia faz uma parte mais ampla do estudo dos climas. Suas observações tomam forma cartográfica. Ela se põe a retraçar, pelo menos em seus aspectos gerais, a repartição de certos grandes fenômenos, oferecendo-nos uma imagem de reações recíprocas exercidas pelas diferentes partes da Terra, oceanos e continentes. É, de modo breve, a expressão do parentesco que une as regiões terrestres.

Devo passar rapidamente sobre estas considerações que me levarão facilmente para fora do meu objeto. Qual não é o interesse no desenvolvimento crescente das pesquisas de geografia botânica, beneficiando-se da experimentação e de uma investigação cada vez mais íntima sobre as relações das plantas com o clima e o solo! Limitemo-nos a destacar que as ciências que se ocupam do homem também encontrarão, nos fatos advindos destas regiões escondidas na obscuridade dos continentes, fontes de ensinamentos. O simples material de civilização que nelas descobrimos - que se exprime nos modos de habitação, armas, roupas, e que se manifesta em nós pelas amostras e imagens que povoam os museus etnográficos - pode ter um novo sentido e um novo alcance. Um povo, seja ele primitivo (e, diremos voluntariamente, quando mais primitivo ele for), imprime sua marca sobre os objetos que fabrica, tomando emprestados da natureza ambiente sua substância e modelos. Tais objetos falam sobre estes povos. Por mais distantes que estes povos estejam do mar e das grandes vias de comunicação, mesmo em suas regiões existe um comércio elementar. Aqueles objetos passam de mão em mão e se propagam por imitação, de sorte que sua repartição (se ela for estudada criticamente) pode lançar luzes sobre relações que escapam à história, mas nem por isso têm menos interesse entre os grupos mal conhecidos da família humana.

Assim, as ciências da terra, e mesmo certas ciências do homem, acusam uma tendência a se desenvolver num sentido mais geográfico. Esta tendência surge das próprias necessidades de sua evolução. Ao avançar, elas têm reencontrado a geografia em seu caminho. Na realidade, tudo isso é apenas expressão da unidade fundamental que as religa. A relação entre elas não consiste apenas em simples transferências de resultados, mas no fato de que estão mutuamente impregnadas em seus métodos. Que a geografia se aproveite da influência que daí repercute, nada mais natural. Para ela, certamente não é de pouca importância iniciar-se no jogo de forças que modifica a superfície terrestre. A diferença não é pequena entre considerar os fatos como entidades fixas ou vê-los como a consequência de processos anteriores - processos tão lentos quanto o funcionamento de um relógio. Não é fato sem implicação a aquisição de vias mais nítidas sobre as condições de concorrência e de luta que presidem a repartição dos seres, 
pois a inteligência do estado de equilíbrio instável que governa as relações da natureza vivente é a única que pode explicar as condições nas quais se exerce a atividade humana.

No grupo das ciências da terra, a geografia sempre guardará sua tarefa, tarefa que ela não deve perder de vista. Sem dúvida, o estudo da Terra, considerada em seu conjunto, responde mesmo à sua definição: ela persegue o conhecimento das leis gerais, mas pretende estudá-las em sua aplicação nos diversos ambientes. A geografia se interroga sobre o meio de explicar as diferenças de fisionomia apresentadas pelas regiões. Eu acreditaria, voluntariamente, que estas diferenças (provenientes do espetáculo que a Terra expõe a nossos olhos) são o princípio mesmo da curiosidade que despertou a origem do instinto geográfico. Desde que o homem, superando o círculo estreito em que toda a curiosidade se enfraquecia, pôde comparar outros países ao seu, sua atenção encontrou novo alimento; seu espírito, um objeto de interrogação. Esta arejada impressão de curiosidade não se manifesta quando lemos as narrativas destes velhos "contadores" de histórias que são Heródoto, Rubrouck e Marco Polo? É a sensação dessas diversidades que desperta, pode-se dizer, o geógrafo que dorme em cada um de nós.

Consequentemente, geógrafos não menos autorizados pensam que é em direção aos estudos regionais, consistindo em explicações descritivas e racionais ao mesmo tempo, que devem ser direcionados, hoje, os esforços do trabalho geográfico. Esta visão inspira-se num sentimento justo. Ela nos parece uma das lições que resultam dos fatos que aqui tentamos reunir. $\mathrm{O}$ que surpreende, depois que pudemos comparar sobre uma escala maior os fenômenos da superfície terrestre, é a maravilhosa variedade de combinações que eles apresentam. Em todos os lugares, tais fenômenos se mostram regidos por leis gerais, mas igualmente modificados por circunstâncias locais de solo, relevo, clima e pelo cruzamento entre todas as causas que concorrem a determinar a fisionomia das regiões. A gama de diferenças se estende. O clima desértico não se imprime da mesma forma sobre o Saara e sobre os desertos da Austrália e da América. Encadeamentos diferentes de fenômenos diversificam regiões que, em certos aspectos, são análogas. Cada região é a expressão de uma série particular de causas e efeitos.

Enquanto as observações estiveram mais ou menos confinadas às zonas temperadas (onde as influências são amortecidas e que são, em outras partes da Terra, submetidas, após longa data, à ação do homem), a relação que une os fenômenos entre si poderia ser menos aparente. Esta relação se mostra viva nas regiões sobre as quais o emprego pujante do 
clima excessivo torna-se um peso ${ }^{11}$ ou naquelas dos climas com chuvas periódicas. Tenho por testemunho as expressões que escapam, em presença destes contrastes terrestres, da boca dos exploradores. Vejamos Barth ou Nachtigal no momento em que, depois da travessia do Saara, entraram na região de chuvas regulares do Sudão. Este último dizia: "Quando os primeiros clarões do dia iluminavam os arredores, nos sentimos transportados para outro mundo". ${ }^{12}$ Ele mostra então "a floresta clara, contínua, na qual as acácias espinhosas ainda dominam, é verdade, mas onde mostram árvores novas, porém altivas, mais ricas em sombras e em folhas...". Em circunstâncias parecidas, encontramos esta observação de cenas diferentes entre todos os viajantes atentos. Não menos vivamente, Prjevalski a exprime quando vê suceder, na solidão medonha do Tibete ocidental, as montanhas cobertas pelas chuvas de verão, onde nascem alguns dos grandes rios da China e da Indochina. ${ }^{13}$ Os Surveyors americanos não conseguem se superar quando, para além do grau $100 \mathrm{de}$ longitude, entraram nas regiões das estepes. ${ }^{14}$

Se examinamos mais de perto estas impressões nascidas no choque com os lugares em si, reconhecemos que há neles, sem dúvida, seguindo os hábitos de cada um, um aspecto particular no qual eles se mostram mais sensíveis. Para o naturalista Nachtigal, a vegetação; para Barth, geógrafohistoriador, o movimento da atividade humana. Mas, entre todos, o que domina é uma impressão de conjunto, da fisionomia geral na qual contribuem o solo, o céu, as plantas, as obras humanas. Onde melhor procurar que nestes testemunhos espontâneos a indicação do método natural? Analisar estes elementos para desvendar sua ação recíproca, sem esquecer, contudo, que se trata de realidades concretas: tal é a tarefa do geógrafo sobre o tema vivo e inesgotável que a natureza lhe oferece.

A geografia é uma velha ciência, mas ela se rejuvenesce periodicamente à medida que mergulha em suas fontes vivas, ou seja, na diversidade dos espetáculos terrestres. Quando o mundo pareceu aumentar pelas descobertas do século XVI, viu-se constituir os alinhamentos da geografia geral. Foi com os materiais recolhidos pelos viajantes do século XVIII na América e na Ásia que Buffon assentou as bases da geografia zoológica. Do espetáculo das "regiões equinociais", Humboldt relaciona suas vias fecundas sobre a fisionomia vegetal. Para ele, uma multidão de novos dados entra em circulação, se agrupa, se coordena e fornece a

11 Sobre estas regiões, ver as reflexões de MIDDENDORFF (Reise in den äussersten Norden und Osten Sibiriens. - Sibirische Reise, t. IV, parte II, p. 286).

${ }^{12}$ NACHTIGAL, Sahara und Sudan, I, p. 558.

${ }^{13}$ Quarta viagem (Peterm. Mitteil., 1889).

${ }^{14}$ C. Thomas, $6^{\text {th }}$. Annual Report. U.S. Geol. Survey of the Territories, 1873. 
matéria da geografia comparada. Em nossos dias, quando o comodoro Maury abriu perspectivas sobre a geografia do mar e quando o mundo das altas montanhas começou a liberar seus segredos, Elisée Réclus retraça em um belo livro a harmonia e a correspondência do organismo terrestre. Ao mesmo tempo, Oscar Peschel abordava o difícil problema da interpretação das formas de relevo e dos continentes. Se esta tentativa era então prematura, logo deixou de sê-la, como provam os trabalhos que apareceram depois na Alemanha, na Escócia, nos Estados Unidos e na França. Assim, chegamos gradualmente em direção ao estudo das leis e das causas. Hoje, as condições de trabalho permitem proceder com mais segurança que outrora. Uma ciência que analisa e compara, que dispõe de um grande número de dados precisos para determinar tipos e tentar classificações, que esclarece, das realidades que estuda, o efeito combinado de leis gerais, porta as características da idade de maturidade. O caminho foi longo, mas, no fundo, não houve nada de regular e natural no andamento da ciência geográfica.

É neste espírito que eu me proponho estudar com vocês a geografia da França. Pela variedade e complexidade de questões que levanta, o tema é difícil. Quantas razões, portanto, para tentar! Eu ficaria feliz se conseguisse retraçar uma imagem que não fosse muito imperfeita deste país que tanto viu, sofreu e reparou e que, depois de 2 mil anos, exerce uma tal atração sobre os homens. 